\title{
Agri-urban patterns in Mediterranean urban regions: the case study of Pisa
}

\author{
Irune Ruiz-Martinez (D) ${ }^{a}$, Marta Debolini $\mathbb{D}^{\mathrm{b}}$, Tiziana Sabbatini ${ }^{c}$, Enrico Bonaric, Sylvie Lardon ${ }^{\mathrm{d}}$ \\ and Elisa Marraccini (D) $^{\mathrm{e}}$ \\ aResearch Institute of Local Development, University of Valencia, Valencia, Spain; bUMR 1114 EMMAH INRAE/AU, \\ Avignon, France; 'Scuola Superiore Sant'Anna, Institute of Life Sciences, Pisa, Italy; 'Université Clermont Auvergne, \\ AgroParisTech, INRAE, VetAgro Sup, Territoires, Clermont, France; eUP INTERACT 2018.C102 UniLaSalle, Beauvais, \\ France
}

\begin{abstract}
Urban regions require planning tools in order to manage agricultural areas under urban pressure. The aim of our paper is to test an analytical framework that combines both the composition in urban and agricultural land covers and their spatial configuration into four general agri-urban patterns: isolated fields, urban belt fields, periurban agricultural areas and rural areas. We evaluated the spatial distribution and the changes of such patterns in the short-term (2003-2011) starting from Spot images for the case study of Pisa, Italy. The results indicate an increase of the most urban patterns despite continuing to have cash crops, a stability of periurban agricultural land patterns although highly fragmented, and a decrease of the rural agricultural land patterns. The applied methodology can help to identify new measures and actions suitable in order to strengthen the relationships between city and agriculture existing in urban regions.
\end{abstract}

\section{ARTICLE HISTORY}

Received 2 July 2020

Accepted 4 October 2020

\section{KEYWORDS}

Urban planning; periurban; land fragmentation; farming systems; medium-sized regions

\section{Introduction}

Climate change and land take are some of the main challenges confronting European lands (European Environment Agency [EEA], 2019b). Likewise, land take was concentrated around large urban centers between 2000 and 2018 such as in France (48\%), Germany (37\%) and Italy (22\%) being particularly significant in Turkey, Spain and United Kingdom with the $179 \%, 92 \%$ and $68 \%$ of total area of the country, respectively. The most affected type of land corresponds to arable land and permanent crops (51\%) and pastures and mosaic farmland (27,5\%) (EEAb, 2018) Beyond land take, the most significant land cover changes occur in the periurban areas (Beckers et al., 2020; Wadduwage, 2018), thus reducing the capacity of these areas to supply ecosystem services, including the local food supply (Filippini et al., 2019; Moragues-Faus \& Marceau, 2018). This trend goes on the opposite direction of the recently approved European green deal (European Comission [EU], 2020). In fact, the EU 2020 strategy focused on the explicit need to advance the understanding of mutually beneficial relations along urban-rural areas, e.g. in providing food for cities.

Up to the mid-1990s, 3\% annual of farmland throughout the Mediterranean region was lost to urbanization, and $60 \%$ of this land was highly suitable for agriculture (EEA, 2018). Ceccarelli et al. (2014) found that $40 \%$ of the land urbanized since 1954 in Emilia Romagna region (Italy) was of high agricultural quality, and Zdruli (2014) estimated that the same trend of farmland loss will continue for the next 30 years. A literature review from Debolini et al. (2018) found that land use and land cover 
changes in the Mediterranean basin have shown increasingly different development trajectories. For instance, mountain areas face the abandonment of traditional, extensive production systems (Romero-Calcerrada \& Perry, 2004) while peri-urban areas reduce their agri-environmental function due to urban pressure (Tavares et al., 2012; Zasada, 2011) or re-locate their agricultural areas (Opitz et al., 2016). Further, Debolini et al. (2018) have highlighted that most of the case studies on land use and cover changes in Mediterranean basin focus on periurban inland areas mainly in terms of urbanisation or agricultural abandonment.

An urban region has been here defined as a region recognized by local planning policies as urban (Forman, 2008). Different types of urban regions exist, depending for instance, on the morphology of the urbanized areas, e.g. monocentric or polycentric (Kloosterman \& Musterd, 2001) or on the size of the urban areas $(O E C D, 2020)$. Although the decrease of agricultural areas in urban regions is a main issue for policy-makers and urban planners, only metropolitan areas have been largely investigated, even in Mediterranean regions, both in terms of land use changes and of planning tools. For instance, research has been done on Athens (Chorianopoulos et al., 2010; Gounaridis et al., 2018; Salvati et al., 2013), Rome (Salvati, Gemmiti, et al., 2012; Salvati, 2013, 2015), Istanbul (Çakir et al., 2008); Valencia (Carrasco \& Puebla, 2014; Prytherch \& Boira Maiques, 2009), Alicante (Morote \& Hernández, 2016) and Barcelona (Catalán et al., 2008; Dura-Guimera, 2003), showing either trends of urban growth or the impact of agricultural areas from metropolitan to urban regions of mediumsized cities over the large time period of 20 and 30 years.

In terms of planning, some efforts have been made to regulate urban growth at the expense of agricultural areas, e.g. the contribution of Gren and Andersson (2018): but there are still few effective direct planning tools and they need the implementation of decision support systems (Soulard et al., 2017). More examples of such direct planning tools are agrarian parks in the cities of Barcelona (Paül \& McKenzie, 2013) and Milan (Giacchè et al., 2012) or agricultural protected areas described for example, in Portugal by Abrantes et al. (2016), who also questioned the effectiveness of such planning tools in protecting agricultural areas. Other studies especially warned about the lack of these planning tools close to the city (Pileri \& Maggi, 2010). In most cases, the planning tools consist of different models of protected areas such as the market-based land conservation programs (Jiang \& Swallow, 2015), whereas the removal of intermediate collective structures, such as farmers' cooperatives, can facilitate in some cases the urbanization process and foster the fragmentation of properties (Debolini et al., 2015). However, land recycling or use of urban areas that have been abandoned for other uses (for urban agriculture) is considered as a key planning tool for achieving the goal of no net land take by 2050 (Decoville \& Schneider, 2015; EEA, 2018a, Sanz Sanz et al. (2017), and Gren and Andersson (2018) demonstrated that it is possible to rethink to urban planning starting by a characterization of both urban and agricultural activities. This need is also reflected in other studies encouraging urban planners to use their substantive knowledge of 'space shaping' to create sustainable urban food systems (Filippini et al., 2019; Morgan, 2015).

However, further analyses are needed to link farm dynamics to fringe landscape particularly in medium-sized urban regions (Galli et al., 2010; Pileri \& Maggi, 2010; Serra et al., 2017). In that sense, Moreira et al. (2016) identified some static and dynamic types of municipalities based on the main land cover composition and on some fragmentation metrics, highlighting that the most dynamic municipalities were those located in a buffer surrounding the city center. However, Marraccini et al. (2015) showed that at the urban region level in the Mediterranean region several dynamics involving either direct urbanization or other land-use changes can coexist in these areas, influenced by both the type of urban region (metropolitan or mid-sized urban area) and the location of the urban region (north or south of the Mediterranean). Moreover, the same authors found wide differences of landuse changes in the rural-urban fringe: more afforestation and abandonment process in the urban regions of north, whereas agricultural conversion closer to urban use occurs mainly in urban region of south Mediterranean. In general, these studies underlined three challenges for further research. First, a focus on medium-sized urban regions that have often be neglected as research object or as a target for regional or urban planning (Kunzmann, 2010). Secondly, metropolitan urban regions are 
characterized by fast dynamics, mainly in terms of urbanisation that are not easily detected through long-term studies (Abrantes et al., 2016; Marraccini et al., 2015; Pileri \& Maggi, 2010), thus asking for more short-term studies to be coupled to long term one. Finally, there are new demands in urban planning, more oriented on functional units rather on land-use patterns (Sanz Sanz et al., 2017).

In order to take into account these challenges, our goal was to test an analytical framework of agri-urban patterns developed by Marraccini et al. (2017) in a Mediterranean medium-sized urban region and in a short-term time span, to answer to urban planners demands on new planning policy to be developed in Pisa urban region in 2020 (Tuscany, Italy) (Comune di Pisa, 2020) since the agriurban patterns can give information about the agricultural productions and their sustainability.

\subsection{Analytical framework and objectives}

Existing literature on the characterization of rural-urban gradients in urban regions focuses on typology-based models of municipalities according to their urban or rural character, e.g. Moreira et al. (2016) or Gonçalves et al. (2017). Recently, other models are emerging taking more explicitly into account other spatial units than municipalities or at least articulating them with types of municipalities and focusing on functional relationships between urban and rural land uses (Sanz Sanz et al., 2018). Marraccini et al. (2017) proposed an analytical framework linking the patterns and functions of agricultural and urban areas across a rural-urban gradient. It is based on other spatial units than municipalities, and in term of implementation it does not need time-consuming inputs as such interviews. This analytical framework is based on the pattern/function relations already used in landscape ecology (Alberti, 2005; Forman, 1995) or in landscape agronomy (Rizzo et al., 2013) applied to the specific question of urban planning. Two features are considered important in pattern/ function relations: land use/cover composition and configuration. About land use/cover composition, the hypothesis is that if the urban land use increses, then the production function will decrease but other functions can still exist, e.g. leisure or ecological functions. About land use configuration, the hypothesis is that the production function decreases if fragmentation and isolation increase (Figure 1). The aerial photographs (Geoscopio cartoteca, 2016) illustrate different compostions and configurations of agricultural and urban land uses, from the more urban, poorly fragmented where other functions other than production functions dominate to the more agricultural, poorly fragmented and where the production functions dominate.

We applied this analytical framework to the case study of Pisa (Italy), a medium-sized urban region located in a coastal Mediterranean area, in order to better identify the main agri-urban patterns and their functional changes.

The analytical framework developed by Marraccini et al. (2017) identifies four general agri-urban patterns, which can be described throught their landscape functions (Figure 2): 1) Isolated fields: the urban setting constraint the productive function, but it is possible to enhance other social and environmental functions (e.g. leisure, gardening, areas of cultural value, urban biodiversity), thereby reducing the environmental impact of buildings for instance, in terms of mitigating urban heat island (Gunawardena et al., 2017), p. 2) Urban belt fields: these are the agricultural areas adjacent to a dense urban areas. They thus represents the belt areas, directly at the interface between city and agricultural fields. Agricultural fields in this belt offer interesting prospects for direct selling and other forms of small local trade mainly dedicated to fresh produce. Traders and consumers can access food easily. However, they are highly exposed to urban pressure. Land-use conflicts are common in these belt areas, as reported by Darly and Torre (2013), e.g. contesting the creation of urbanised sites, the spreading of sewage sludge, the use of pesticides nearby houses; 3 ) Peri-urban agricultural areas: they are located outside the belt areas, where the town is no more dense. There is a coexistence of urban and agricultural land uses, with a higher fragmentation than in belt areas. Periurban areas have the potential for an enhanced agricultural production, both in terms of fresh produce and commodities. Filippini, Lardon, et al. (2018) or Scheromm and Soulard (2018) have highlighted that both productions can coexist in these peri-urban areas, and adapt with them depending for instance, 


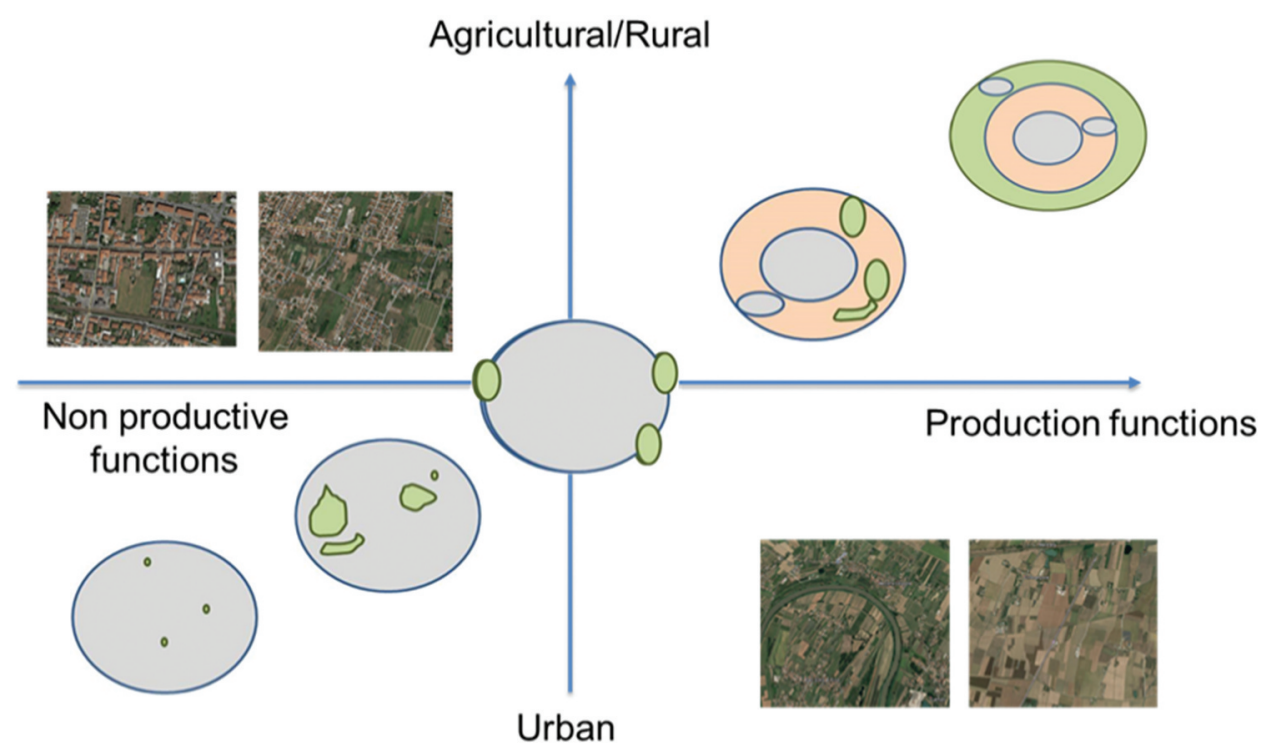

Figure 1. Illustration of the patterns/functions relationships in urban regions in a gradient of urban and agricultural land use. In grey, the urban areas more dense or sprawled; in green the agricultural or green areas, more dispersed or continuous; in rose, the periurban areas characterized by a fragmentation of both urban and agricultural or natural land uses.

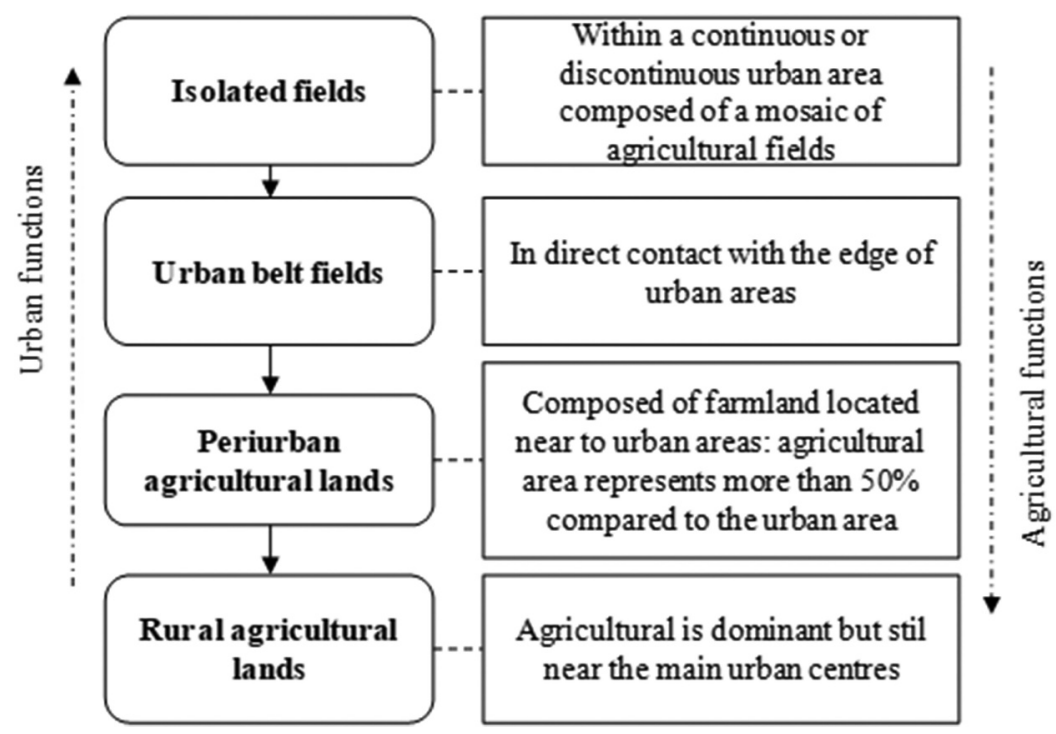

Figure 2. Scheme of the four agri-urban patterns resulting in the analytical framework developed by Marraccini et al. (2017)

on land tenure, constraints in urban planning or even facilities for alternative food networks; 4) Rural agricultural lands: this pattern is found when the dominant land use is agriculture and urban areas are isolated, e.g. isolated houses or small villages) or in form of infrastructures, e.g. roads, industrial areas. In this case, the multiple functions of agriculture are fully expressed as well as the production functions. The productions can be trade to the city as fresh or for processing through short supply chains, and also to wider markets as a commodity (Filippini, Lardon, et al., 2018; Mawois et al., 2011; 
Scheromm \& Soulard, 2018; Tedesco et al., 2017). Moreover, the applied methodology in this study can help to identify new measures and actions suitable in order to strengthen the relationships between city and agriculture existing in urban regions. It is showing sign to apply not only measures on short supply chains and $\mathrm{KmO}$ but also considering the patterns such as residual and isolated agricultural areas as isolated maintenance and even encourage a type of crops for these areas.

\section{Materials and methods}

\subsection{The urban region of Pisa (Italy)}

The urban region of Pisa, a medium-sized city located in Tuscany, Italy, $\left(43.7167^{\circ} \mathrm{N}, 10.4000^{\circ} \mathrm{E}\right)$ is illustrative of the Mediterranean urban regions located in coastal plains. These regions are characterized by an intense urban pressure but also by seasonal summer tourism, and are sensible to loss of agricultural areas and land degradation (Marraccini et al., 2015; Romano \& Zullo, 2014; Salvati, Gemmiti, et al., 2012). The region of Pisa has an area of $475 \mathrm{~km}^{2}$ and a population density of almost 400 inhabitants per $\mathrm{km}^{2}$ according to the latest population census (Comune di Pisa, 2015). This urban region resulted from the joint collaboration of six municipalities that voluntarily decided in 2008 to have common urban planning tools (Comune di Pisa, 2008). (Marraccini et al., 2015) (see Figure 3). Three significant land cover trends have been highlighted over the past 30 years: an urbanization rate of $3 \%$, the increase in the forest area and the resulting decrease in agricultural land (Lardon et al., 2017). As shown in Figure 3, the city of Pisa is located in a plain area, and has a compact centre and a radial road system extending to the surrounding agricultural areas. Population growth has been slow and has been increasing in the surrounding areas.The municipalities established territorial planning tools years ago, whereas the regional government provides the framework rules such as the last Territorial and Landscape Plan of 2014 in the case of the Regione Toscana (2014). The focus of this Plan was on targeting the processes of urbanization and, where possible, reducing the already
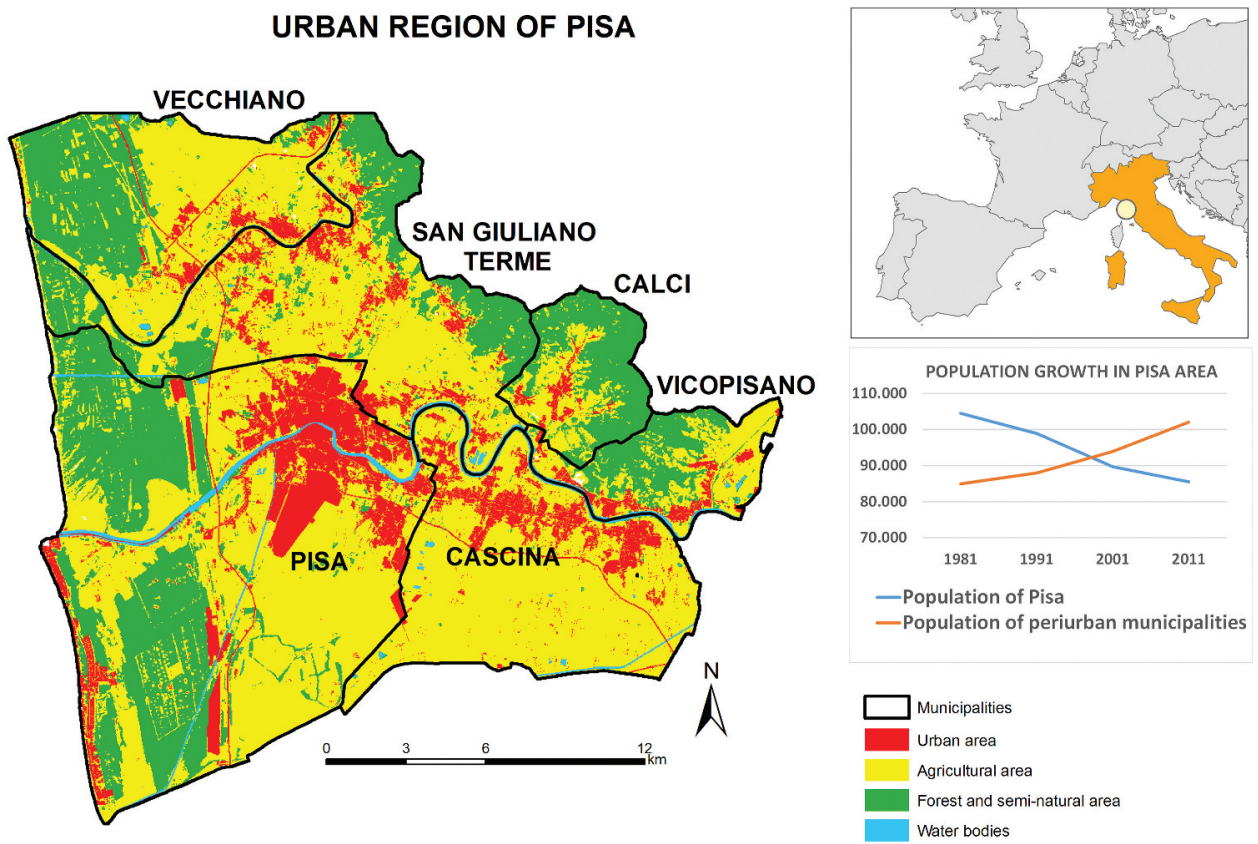

Figure 3. Location of the case-study area in the urban region of Pisa (Tuscany, Italy). Sources: administrative boundaries: Regione Toscana (2016), Land cover: Corine Land Cover (2012) and Comune di Pisa (2015). The names in capital letters indicate the municipalities belonging to the urban region. 
high degree of land consumption to re-qualify floodplains, protect natural values and increase the ecological permeability. For these purposes, the Plan suggested the preservation of rural areas and the enhancement of agricultural open spaces by zoning the entire region in two classes, i.e. areas where urban growth is already possible and rural agricultural areas where the urban growth is strictly managed. Therefore, the zoning and the characterisation of the urban and agricultural characters of urban regions were issues at stake for urban planning in the region and a main motivation for this study. After 2014, several political negociations undergone among the municipalities but for political reasons, the plan was firstly suspended, then restarted but limited only to the two main municipalities of Pisa and Cascina (Comune di Pisa, 2020).

\subsection{Overview of the method}

The method consisted of two main steps (Figure 4). First, we built two land-use databases (2003 and 2011) and quantified the main classes of land use/cover changes through remote sensing and photointerpretation. Then, we applied the analytical framework developed by Marraccini et al. (2017) for both years and then conducted a deeper analysis of the agri-urban pattern dynamics and examined the landscape structure and configuration (fragmentation) using landscape metrics. The overall methodology is shown in Figure 4.

\subsubsection{Data collection and preprocessing}

Two satellite SPOT images ('Satellite Pour l'Observation de la Terre') were acquired from the ISIS Programme of the French CNES (Centre National d'Etudes Spatiales), for the two dates of 2011 and 2003, in order to assess land use/land cover changes. In addition, two aerial photographs (scale 1:10000), one about June 2003 in black and white and one from October 2010 in colour, provided by Geoscopio cartoteca (2016) were selected as base for ground references. Images from Google Earth taken in June 2003 (black and white) and April 2011 (colour) were also used to achieve more detailed crop indentification using Street View in April-August 2011.

\subsubsection{Semi-supervised classification}

The 2011 image was classed using a semi-supervised classification through the ERDAS IMAGINE 8.5 software. Four main land cover classes were assessed: urban, agriculture (which included permanent and annual crops), natural vegetation and forest, and water (e.g. sea, rivers and lakes). Moreover, 12 main crops were subsequentely differentiated: wheat, corn, legumes, vineyards, olive, pasture and forage, vegetables, greenhouses, sorghum, colza, fallow and livestock. These classes have been choosen because they represent the main types of land cover in the study area. Subsequently, the availability of colour photos in 2011 allowed us to validate and correct land uses at crop level (e.g. wheat, corn) using Street View, as shown in Figure 5. An accuracy assessment was then applied using the kappa variable (GRASS Development Team, 2019) in Qgis software (QGIS Development Team, 2020) in order to evaluate the probability of correct classification. For 2003 we obtained the land use map trhough direct photointerpretation, digitalizing the fields and thus directly obtaining vectorial cartography. This was because we could not obtain ground control points for automatic remote sensing analysis. The minimum cartographic unit was 0.01 ha what is implying a fairly highresolution image. Even so, it was possible to obtain the four main land cover classes.

\subsubsection{The spatial pattern analysis}

Starting from the land-use maps created, we applied the analytical framework to the urban region of Pisa. The criteria for spatial pattern identification were as follows: plots inside the urban area were denoted as isolated fields; fields adjacent to the boundary of the urban area were classified as urban belt; agricultural areas within $1 \mathrm{~km}$ distance beyond the dense urban area were classified as periurban; and land beyond the peri-urban areas was classified as rural. To identify the peri-urban agricultural areas we sought to remove the influence of urbanization where the average size of 


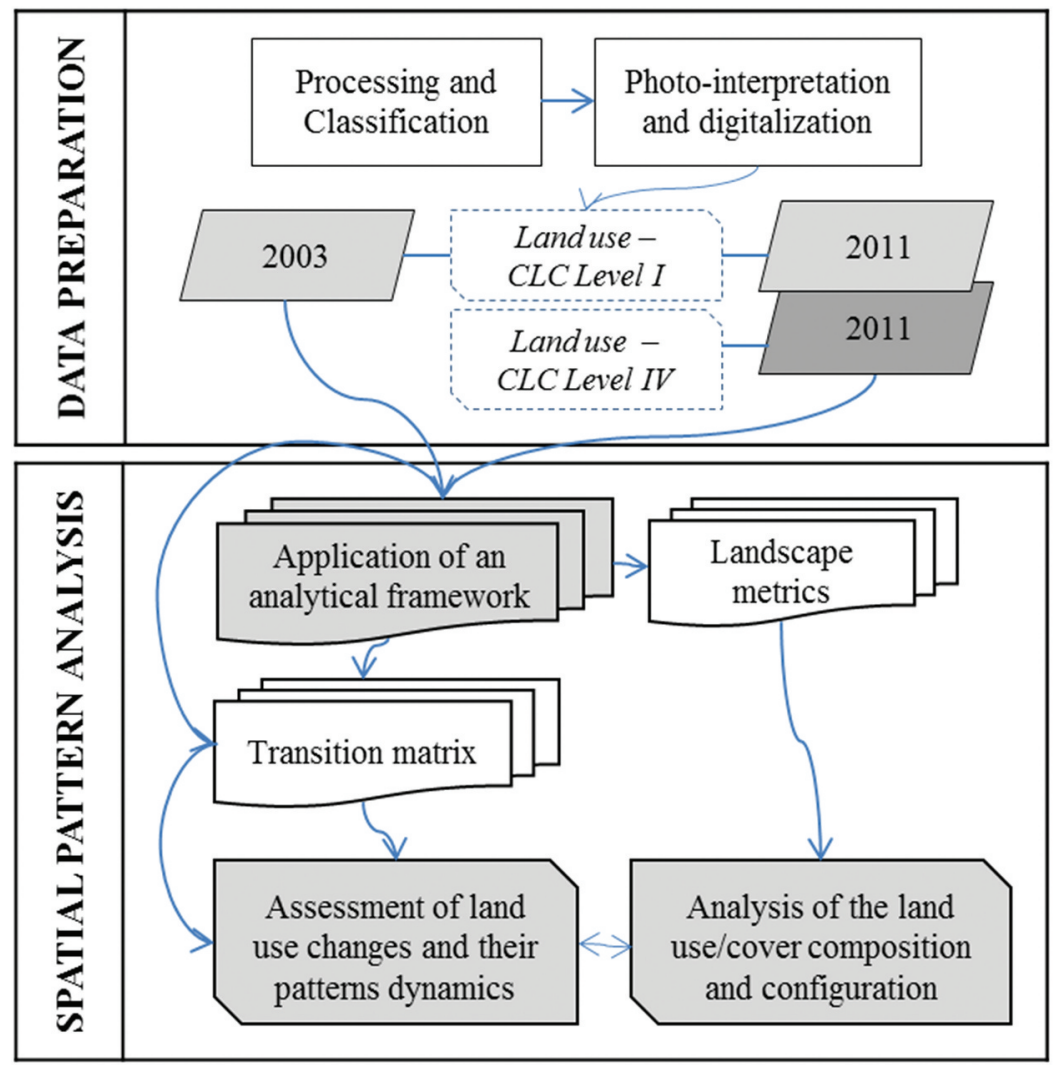

Figure 4. Overview of the method with the two steps of data building and data analysis.

the fields began to increase. In this sense, we defined peri-urban areas just in geographical and not in socio-ecological terms through variables such as employment, commuting or population density. Three options were tested to set the threshold of peri-urban areas from the urban belt: $500 \mathrm{~m}, 1 \mathrm{~km}$ and 1,5 km. After a multidisciplinary (agronomist, geographer and a urban planner) expert validation of the three options, $1 \mathrm{~km}$ was chosen as the distance to define the limit of periurban areas, as the most suitable option according to the structure of the urban region.

Once the two land cover and agri-urban maps (2003 and 2011) were obtained, we evaluated the changes in agri-urban patterns through a transition matrix analysis (Marraccini et al., 2015). The transition areas matrix is the number of pixels that are expected to change from each land cover type to every other land cover type over the specified number of time units. According to the results of the transition matrix, the growth rate (1) of each agri-urban pattern over the study period was calculated as

$$
\text { (LUT1 - LUT0)/LUT0 }
$$

where LUT1 refers to the total land use hectares at time 1 (2011) and LUT0 the total land-use hectares at time 0 (2003). To make our data comparable with other case studies, we followed Taubenböck et al. (2014) and we calculated the annual growth rate (2) as 


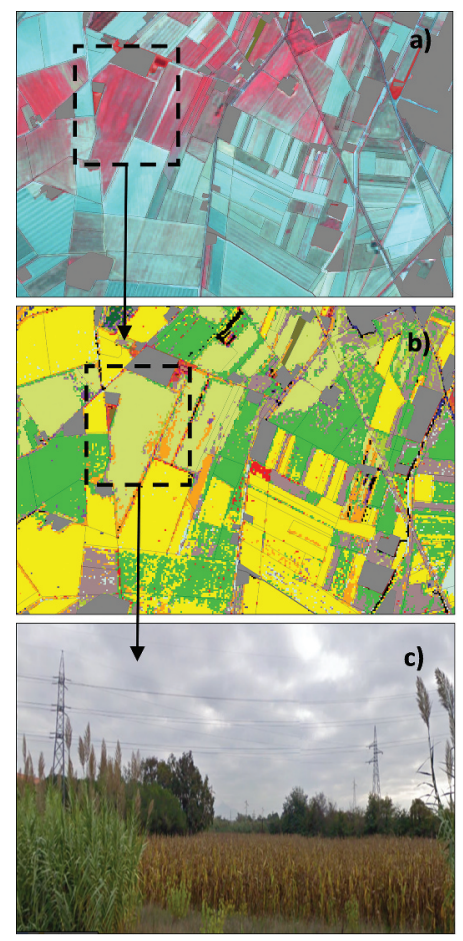

a) Spot satellite image, $10 \mathrm{~m}$ resolution (2011)

b) Semi-supervised classification (2011)

c) Google Street View 2011 - example of land use identification at crop level, e.g., corn field.

Figure 5. Spatial arrangement method (scale 1:10.000; projected coordinate system WGS84_32N).

$$
\left[\left(\frac{L U T 1}{L U T 0}\right)^{\frac{1}{T n}}\right]-1,
$$

where $T_{n}$ is the time interval between the two land cover databases. We then repeated the same analysis for the four agri-ruban patterns in the urban region.

To identify the different processes leading to the observed land cover changes, we analysed the fragmentation to interpret the transition from more rural to more urban agri-urban patterns. Fragmentation has been defined by Forman (1995) to the breaking of an object into pieces (which may be widely and unevenly separated). Different approaches can be applied to calculate landscape metrics in urban areas using either grid cells as geographical units or an index for each patch, such as proposed by La Rosa and Privitera (2013). We applied both approaches and compared the results. First, we calculated different metrics in vector format using spatial data analysis tools with Arcgis 9.3 (Esri, 2008), including the number of patches (NP), the class area (CA) and the mean nearestneighbour distance (MNN) among patches (dc). They were then aggregated into a single fragmentation index (F) (3)

$$
\begin{aligned}
& (F)=\frac{C A}{N P} * R \\
& R=2 d c\left(\frac{\lambda}{\pi}\right)
\end{aligned}
$$

where (R) (4) is a dispersion index (Gurrutxaga San Vicente, 2003). The proposed index is inversely proportional to the degree of fragmentation; thus, an increase in the index value is associated with 
Table 1. Spatial metrics description to understand the urban-rural change (McGarigal \& Marks, 1995).

\begin{tabular}{ll}
\hline NP & Total number of patches. \\
\hline CA & Class area (CA) is the total area of each of the land use patterns. \\
MNN & The mean nearest-neighbour distance (MNN) is defined as the distance from a patch to the nearest neighbouring \\
patch, based on edge-to-edge distance. \\
R & The dispersion index (R) is measured with the mean distance and density of patches. \\
PD & Patch density (PD) represents the number of patches per area and gives insights into landscape fragmentation. \\
LPI & Largest patch unity (LPI) that is a measure of dominance, being the ratio of the largest patch in each class to the \\
total landscape surface, and gives an indication of the class dominance on the landscape. \\
ED & Edge density (ED) is a measure of the contour complexity for the different patches, corresponding to the ratio \\
IJI & between the perimeter of each land use class and the total landscape area. \\
Interspersion and juxtaposition index (IJ) measures the contour complexity of the different patches, \\
COHESION \\
corresponding to the ratio of the perimeter of each land use class to the total landscape surface. \\
It measures the physical connectedness of the corresponding patch. High connectedness of the pattern may \\
indicate suitable landscape configuration.
\end{tabular}

a decrease in fragmentation, and vice versa. The reason for this is based on the index formula, increased fragmentation is related to a reduction in the total class area and a greater number of patches with higher dispersion (R).

Alternatively, class-level metrics were computed using Fragstats (McGarigal \& Marks, 1995) with a $10 \times 10 \mathrm{~m}$ raster, which is consistent with the study topic. According to our aim, we chose six spatial configuration metrics to depict the agricultural landscape patterns. The largest patch index (LPI) represents the spatial configuration of the different patterns and the other five (PD, ED, COHESION, $\mathrm{IJ}$, and $\mathrm{Al}$ ) provide information about the structure, as shown in Table 1.

\section{Results}

\subsection{Land-use changes}

The land-use changes resulting from the 2011 SPOT image classification and 2003 direct aerial photointerpretation for the study area are presented in Table 2. The overall accuracy of the first land cover map (2011) obtained from the semi-supervised classification was moderate to fair, as we obtained a kappa $=0.60$ for the land-use map and kappa $=0.40$ for the land use at the crop level map. The general trends for the 2003-2011 period showed an increase in urban and natural areas and a consequent decrease in agricultural areas. The urban growth rate was $+7 \%$ (with an annual growth rate of $+1 \%)$, either at the expense of agriculture and natural areas or in the urban core. The most significant land-use changes, according to the results of the transition matrix analysis, were that 408 ha of farmland was transformed into urbanized land and 415 ha was abandoned and became natural vegetation between 2003 and 2011 (Table 3).

\subsection{Changes in agri-urban patterns}

The agri-urban patterns identified from 2003 and 2011 slightly differ over time. Isolated fields inside the urban region represent a low percentage of the agricultural area (1.2\% and $1.6 \%$ for 2003 and 2011 , respectively), although this share has increased with the densification of the city, with a relative growth rate of $+26.0 \%$. Similarly, the urban agriculture belt $(17.6 \%$ and $19.1 \%$ for 2003 and 2011 ,

Table 2. Percentage of land cover in 2003 and 2011, relative and annual growth rates. (c.f. formulas given in Section 2.3.).

\begin{tabular}{|c|c|c|c|c|}
\hline Land covers & $\%$ T0 & $\% \mathrm{~T} 1$ & Relative growth \% & Annual growth rate $\%$ \\
\hline Urban & $15.1 \%$ & 16. $2 \%$ & $+6.9 \%$ & $+0.8 \%$ \\
\hline Agriculture & 49. $8 \%$ & 48. $4 \%$ & $-2.7 \%$ & $-0.3 \%$ \\
\hline Natural & $33.0 \%$ & 33. $3 \%$ & $+0.8 \%$ & $+0.1 \%$ \\
\hline Water & 2. $0 \%$ & 2. $1 \%$ & $+1.3 \%$ & $+0.2 \%$ \\
\hline
\end{tabular}


Table 3. Transition matrix of land cover changes 2003-2011 (ha).

\begin{tabular}{|c|c|c|c|c|}
\hline \multicolumn{5}{|c|}{ Land cover 2011 (hectares) } \\
\hline $\begin{array}{l}\text { Land cover } 2003 \\
\text { (hectares) }\end{array}$ & URBAN & AGRI & FOREST & WATER \\
\hline URBAN & 7,010 & 0 & 0.4 & 0 \\
\hline AGRI & 408 & 22,803 & 415 & 11 \\
\hline FOREST & 275 & 6 & 15,375 & 0 \\
\hline WATER & 4 & 0.07 & 1.2 & 988 \\
\hline
\end{tabular}

respectively) increased with a relative growth rate (+8.9\%). Peri-urban areas represent about $40 \%$ of the agricultural area (41.5\% and $42.1 \%$ for 2003 and 2011 , respectively) around the urban region, with a relative growth rate of $+1.6 \%$. Rural areas also account for almost $40 \%$ (39.7\% and $37.2 \%$ for 2003 and 2011, respectively) and had a relative growth rate of $-6.4 \%$ in the considered time span (see Table 4).

Higher annual growth rates were observed for urban belt and isolated fields than for peri-urban fields. The matrix of changes (Table 5) was used to analyse the changes in agri-urban patterns. The results showed that 436 ha (2\%) of the periurban agricultural land in 2003 became urban belt fields by 2011 , representing the greatest change in the area, followed by the change from rural to periurban areas (539 ha).

Other changes towards agri-urban patterns were less relevant because they affected only a low percentage of the area and a difference error caused by the resolution of both maps could have produced a data distortion. However, it should be noted that the shift from rural areas has mainly taken place on hillsides what implying the effect by urban pattern (Figure 6).

\subsection{Changes in agricultural land-use composition and increased fragmentation}

Related to these dynamics, agri-urban patterns for 2011 are illustrated in Figure 7(a). The figure shows that land abandonment increases closer to urban regions. The $57 \%$ of shrub and/or herbaceous vegetations associations are mainly in isolated fields. In contrast, arable and permanent crop production increases with the distance from the urban region when arable production is increasing

Table 4. Percentage of agri-urban patterns for 2003 and 2011, relative and annual growth rates (c.f. formulas given in Section 2.3).

\begin{tabular}{lcccc}
\hline Patterns & $\%$ T0 & $\%$ T1 & Relative growth $\%$ & Annual growth rate $\%$ \\
\hline ISOL & $1.2 \%$ & $1.6 \%$ & $26.0 \%$ & $2.9 \%$ \\
UB & $17.6 \%$ & $19.1 \%$ & $8.9 \%$ & $1.1 \%$ \\
PUA & $41.5 \%$ & $42.1 \%$ & $1.6 \%$ & $0.2 \%$ \\
RURAL & $39.7 \%$ & $37.2 \%$ & $-6.4 \%$ & $-0.8 \%$ \\
\hline
\end{tabular}

ISOL means isolated fields, UB, urban belt fields, PUA, = periurban agricultural land, RURAL, rural agricultural land.

Table 5. Transition matrix of agri-urban pattern changes 2003-2011 (ha).

\begin{tabular}{|c|c|c|c|c|c|}
\hline \multicolumn{6}{|c|}{ Agri-urban patterns 2011 (hectares) } \\
\hline $\begin{array}{l}\text { Agri-urban patterns } 2003 \\
\text { (hectares) }\end{array}$ & ISOL & UB & PUA & RURAL & 2003 Total \\
\hline ISOL & 285 & 4 & 0 & 0 & 290 \\
\hline UB & 78 & 3,996 & 0 & 0 & 4,075 \\
\hline PUA & 0 & 436 & 9,240 & 0 & 9,676 \\
\hline RURAL & 0 & 0 & 539 & 8,630 & 9,168 \\
\hline 2011Total & 364 & 4,437 & 9,778 & 8,630 & 23,209 \\
\hline
\end{tabular}

ISOL indicates isolated fields, UB, urban belt fields, PUA, periurban agricultural land, RURAL, rural agricultural land. 


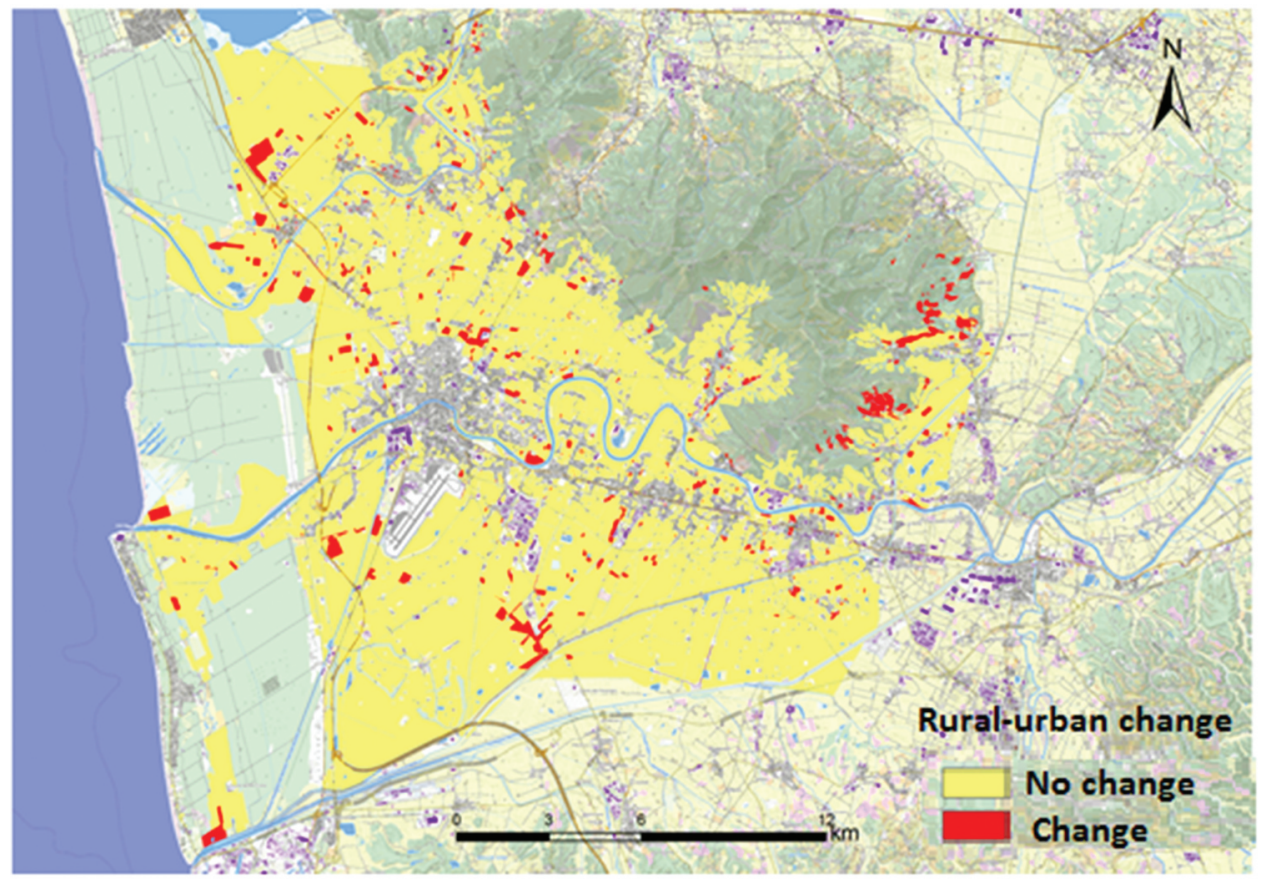

Figure 6. Changes in agri-urban patterns in the urban region of Pisa between 2003 and 2011. Source (Topographic base 1:50.000): http://www502.regione.toscana.it/geoscopio/servizi/wms/.

from $28 \%$ to $62 \%$ in rural areas and permanent crop production from $6 \%$ to $30 \%$ of presence towards the most rural ones. The composition in arable crops is quite different depending on the proximity to urban areas, for instance, isolated fields are manly used for crops that needs an extensive management as such alfalfa. Likewise, the presence of alfalfa represents the $53 \%$ in isolated fields but without agricultural proposes and it could be an indication of abandonment. Industrial crops such sunflower and corn are important in belt fields and periurban areas (Figure $7(b)$ ) with the 20\% approximately of presence showing the permanence of a professional farming also nearby settlements. The existence of winter wheat is remarkable in any event (the $38 \%$ in isolated fields or $42 \%$ in periurban areas) although increasing towards the most rural areas (the 47\%). Similarly, it can be seen how sunflower is lightly increasing with the distance from urban but it is mainly found corn around urban belt (31\%). It seems irrefutable that the production still resist to the urban pressure.

Landscape metrics were calculated at different levels to provide further insights into agricultural fragmentation patterns. The results in Table 6 show the different metrics at patch level. The dispersion values $(\mathrm{R})$ are generally high, especially in the periurban land pattern, due to the high average density of polygons (per $100 \mathrm{ha}$ ) in the study area. Periurban and urban belt patterns present the highest degree of fragmentation $(\mathrm{F})$.

These observations are also confirmed at the class level, in our case is at the agri-urban pattern level (Table 7). Periurban and rural agricultural land patterns present the highest LPI values and are the dominant agri-urban patterns in the urban region. The $\mathrm{Al}$ is high and increases over time while the PD and ED decrease, which suggests increasingly intensified land use. Similarly, the LPI increases over time and the IJ decreases, unlike periurban agricultural land pattern. The effect of urban growth on isolated and urban belt fields is also evident in the decrease in IJ values between 2003 and 2011. The landscape connectivity values slowly decrease going from the rural agricultural land pattern through the more urbanised patterns. 


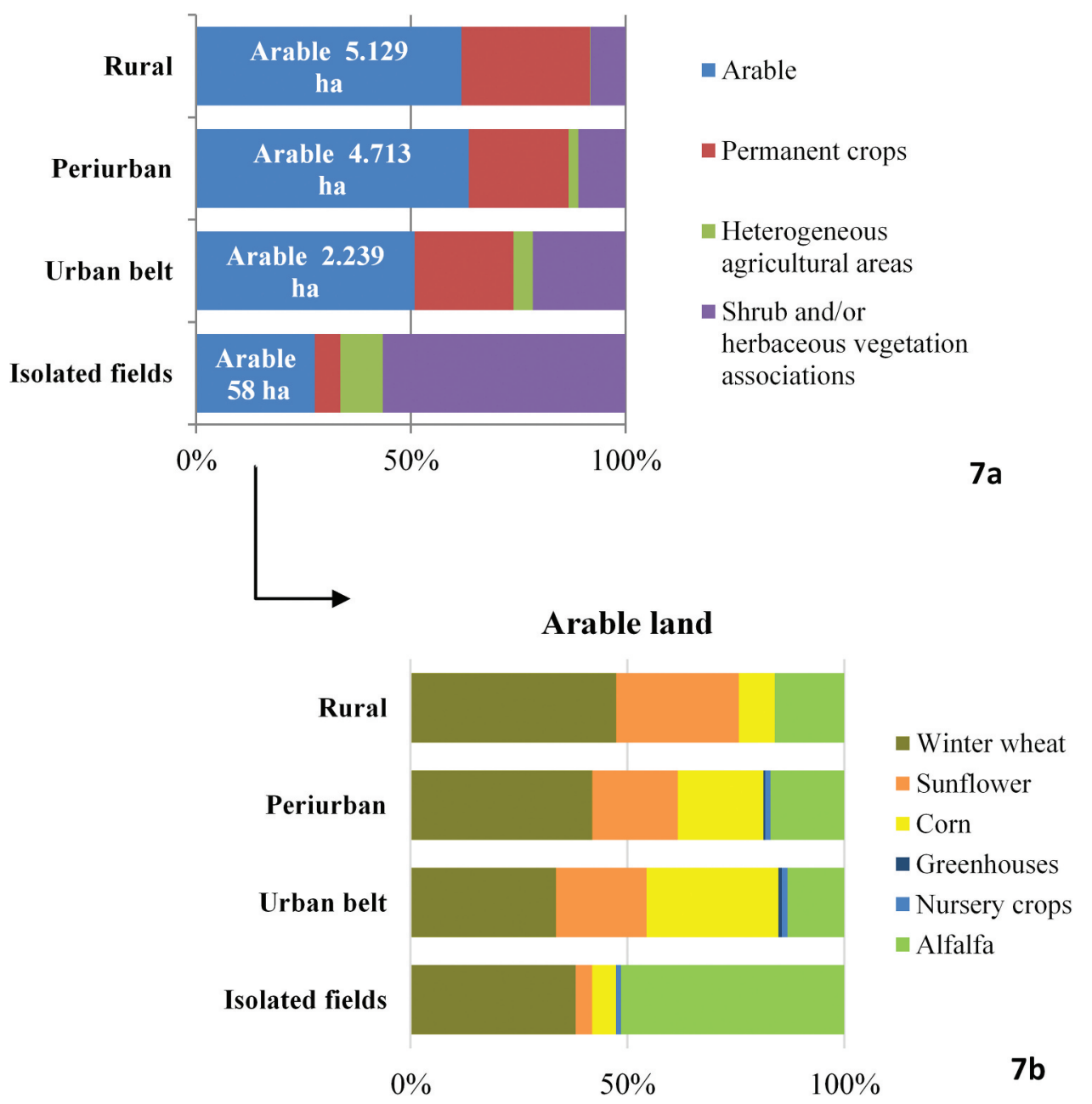

Figure 7. (a) Representative crops for each agri-urban pattern in 2011. (b) Arable land at crop level. Units: hectares (ha).

Table 6. Patch metrics for the land-use patterns at T0 and T1.

\begin{tabular}{lcccccccccc}
\hline Pattern & \multicolumn{9}{c}{ T0 } & \multicolumn{1}{c}{ T1 } \\
\hline & NP & CA (ha) & MNN (m) & R & F & NP & CA (ha) & MNN (m) & R & F \\
\hline ISOL & 535 & 350 & 98,8 & 138 & 0.0047 & 494 & 301 & 93.7 & 127 & 0.0048 \\
UB & 4,820 & 4,858 & 69,68 & 877 & 0.00115 & 4,678 & 4,456 & 70.18 & 883 & 0.00114 \\
PUA & 7,382 & 10,107 & 65,44 & 1,442 & 0.00086 & 7,549 & 9,478 & 62.1 & 1,484 & 0.00084 \\
RURAL & 1,986 & 9,069 & 126,8 & 795 & 0.0045 & 2,691 & 9,064 & 129.1 & 953 & 0.0041 \\
\hline
\end{tabular}

ISOL means isolated fields, UB, urban belt fields, PUA, periurban agricultural land, RURAL = rural land.

\section{Discussion}

Our results showed that in Mediterranean urban regions there are well-differentiated agri-urban patterns defined by a different composition and configuration of urban and agricultural land covers. Moreover, these agri-urban patterns are not stable: they can change, even in the short term (2003-2011), showing an increase of the isolated field and the urban belt field patterns, a stability of periurban agricultural land pattern, and a decrease of the rural agricultural land patterns. These changes can be interpreted in terms of urban growth, particularly in the dense 
Table 7. Results of the class metrics for the agri-urban patterns at T0 and T1.

\begin{tabular}{|c|c|c|c|c|c|c|c|c|c|c|c|c|}
\hline & \multicolumn{6}{|c|}{ T0 } & \multicolumn{6}{|c|}{$\mathrm{T} 1$} \\
\hline Pattern & $\begin{array}{l}\text { PD (n\%) } \\
100 \text { ha) }\end{array}$ & $\begin{array}{l}\text { LPI } \\
(\%)\end{array}$ & $\begin{array}{c}\mathrm{ED}(\mathrm{m} / \\
\mathrm{ha})\end{array}$ & $\begin{array}{l}|J| \\
(\%)\end{array}$ & $\begin{array}{c}\text { COHESION } \\
(\%)\end{array}$ & $\begin{array}{l}\mathrm{Al} \\
(\%)\end{array}$ & $\begin{array}{l}\text { PD (n\% } \\
100 \text { ha) }\end{array}$ & $\begin{array}{l}\text { LPI } \\
(\%)\end{array}$ & $\begin{array}{c}\mathrm{ED}(\mathrm{m} / \\
\mathrm{ha})\end{array}$ & $\begin{array}{l}|J| \\
(\%)\end{array}$ & $\begin{array}{c}\text { COHESION } \\
(\%)\end{array}$ & $\begin{array}{c}\mathrm{Al} \\
(\%)\end{array}$ \\
\hline ISOL & 0.6 & 0.07 & 5.7 & 11.4 & 95.1 & 89.9 & 0.6 & 0.08 & 5.5 & 3.2 & 95.1 & 89.6 \\
\hline UB & 2.3 & 1.5 & 56.9 & 47.6 & 98.8 & 93.0 & 1.9 & 1.6 & 56.2 & 43.5 & 98.7 & 93.1 \\
\hline PUA & 2.4 & 3.3 & 72.3 & 53.2 & 99.1 & 95.7 & 2.1 & 3.5 & 68.8 & 54.5 & 99.1 & 95.8 \\
\hline RURAL & 0.7 & 6.9 & 30.7 & 40.7 & 99.5 & 98.0 & 0.5 & 7.1 & 30.5 & 32.2 & 99.5 & 89.6 \\
\hline
\end{tabular}

PD means Patch Density, LPI Largest Patch Index, ED Edge density, IJI Interspersion and Juxtaposition Index, COHESION Patch cohesion index, Al Aggregation Index. ISOL means isolated fields, UB, urban belt fields, PUA, periurban agricultural land, RURAL, rural.

city area, impacting directly the more urban patterns, and indirectly the more agricultural ones. Previous research on land cover changes in the urban region of Pisa (Lardon et al., 2017; Marraccini et al., 2015) demonstrated that in the medium-term (1980-2010) the main change concerned a loss of agricultural land due to reforestation, re-naturalization and urbanization. This land-use change was significant in other regions of Central Italy due to the lack of urban planning tools (Romano \& Zullo, 2014). Otherwise, new agricultural areas (from forest to agriculture) were mainly created at great distances from the urban center. These first results were consistent with the processes of urbanization and agricultural abandonment that are also observed in similar studies on Mediterranean area (EEA, 2018b) although they followed different patterns depending on the size and type of growth of the city (Marraccini et al., 2015).

Within each agri-urban pattern identified, the part of arable land or abandoned land in 2011 is in accordance with literature: the abandoned land is higher in the more urban patterns and decreases to the more agricultural patterns. Surprisingly, the part of heterogenous agricultual areas as mosaic of different agricultural and abandoned land uses is quite low and completely absent in the rural agricultural land pattern. When scaling to the type of arable crops, our findings were in contrast to the general picture on farming system at the urban region level, oriented to arable crops (Lardon et al., 2017; Ruiz-Martinez et al., 2015). It is also surprising that cash crops such as sunflower and maize are still present in the more urban patterns (namely belt field and periurban fields), showing the permanence of professional farms even very close to the city and not only in rural areas. This is consistent with the recent paper from Scheromm and Soulard (2018) which confirmed the existence of important agricultural spaces inside the cities with a persistence of professional farming. Although there is evidence of abandoned lands in the more urban patterns, we still found an agricultural management in isolated fields even though this management is very extensive, as showed by the important rate of alfalfa in isolated fields. Peri-urban fields and urban belt patterns present the highest degree of fragmentation requiring more attention by urban planners in those areas. Rural areas showed lower levels of fragmentation and have maintained their agricultural land uses. Farmland fragmentation and the fact that vegetable farming systems in Pisa are still connected to conventional food chains as showed by Filippini, Lardon, et al. (2018), are leading to a shifts or loss of production. In other urban regions, vegetable and high-value crops prevail around peri-urban areas due to market-access advantages and the capacity to provide food at all times (Opitz et al., 2016). According to Scheromm and Soulard (2018), this decrease of agriculture affects more small and nondiversified farms whereas larger and diversified farms are probably more resilient also under urban pressure.

\subsection{Agri-urban patterns identification and changes for the sustainable planning of Mediterranean urban regions}

Agri-urban patterns can be considered as a tool for sustainable planning of urban regions. In terms of urban planning, different actions can be taken in terms of management of agricultural 
areas depending on their location within different agri-urban patterns. Romano and Zullo (2014) highlighted wide adverse effects on the most valued agricultural production close to the city where the lack of urban planning tools was undeniable. This location will in fact support different ecosystem services (La Rosa \& Privitera, 2013) or production functions (Lovell, 2010). Provincial and regional policies in Pisa should differ on these aspects around periurban areas: Isolated fields can be preserved as green areas or areas for urban agriculture, such as urban allotment gardens or community gardens. Moreover, they can be connected through greenways (rivers, roads etc.) as biodiversity corridors within the city (Lovell \& Taylor, 2013). Although these patterns are very typical in Mediterranean urban regions (Semple, 1929), they could be the target of specific planning action because of the urban pressure. In other world regions, this pattern has been targeted for specific urban agriculture measures as underlined by Mok et al. (2014). Urban belt fields and periurban agricultural land patterns are both located outside the dense city and even though the proximity with densely inhabited areas is important, they sustain several ecosystem services, and agricultural production functions (Opitz et al., 2016; Zasada, 2011). They can be the target of specific planning measures, which can favour for example, young agricultural entrepreneurs oriented to alternative food networks, leisure both in terms of access to water for irrigation, small buildings, access to fields, regulating land market and so forth. Zasada et al. (2013) and Meraner et al. (2018) described the growing horsekeeping in the urban fringe of Berlin and underlined that urban fringe is particularly attractive for farm diversification activities. Finally, rural agricultural patterns are those where the agricultural functions are higher and the constraints related to urban proximity less important. Depending of the extent of these patterns, different planning tools can be developed to manage agricultural land uses (La Rosa \& Privitera, 2013). All these planning tools have to complaint with the fact that agriculture is an economic activity and that farmers will continue to exploit the land only if it continues to be profitable. For this reason, some conservation tools as the land conservation tools have not proven to be efficient in maintaining active farming in urban regions (Abrantes et al., 2016; Brabec \& Smith, 2002).

In this direction, the development of food planning in European cities (Morgan, 2015) is an opportunity for farmers to find alternatives markets in urban regions, such as alternative food networks (Meraner et al., 2018; Renting et al., 2003), food public procurement (Filippini, De Noni, et al., 2018) and farmers's market (Beckie et al., 2012). Agri-urban patterns could also support food planning in order to find proper strategies and solutions to feed the city and according to the structure of agricultural land within continuous or fragmented urban areas. The Food Plan (Cretella, 2019) and the Territorial and Landscape Plan in the Region of Tuscany were considered as opportunities for the protection of agriculture in turn considering the patterns studied.

The interest in identifying agri-urban patterns can be understood by two well-contrasted models of monocentric and polycentric city in line with what Meraner et al. (2018) argue. In the former, the city extends towards its periphery. The agriculture taken inside tend to disappear, because it is not strong to face land speculation. In the urban belt, public policy can counteract the dynamics of urbanization: creating resistance against the city. At the periphery, there are individual initiatives that are likely to be reached if the urban process expands. In the latter model, which can also be applied to our case study of Pisa, the city refocuses itself from satellite poles. Outside, agriculture could change its approach. Inside, public policies can develop agri-urban projects in their great diversity, relying on local initiatives (Marraccini et al., 2013). Hybrid projects can then be created between inside and outside the urban region; creating synergy between different forms of farming.

\subsection{General interest and applicability of the method}

The application of the method in the urban region of Pisa have demonstrated its feasibility and the insights that agri-urban patterns can provide for urban planning. In order to ally the method in other urban regions, some recommendations can be given. First, the identification of the urban regions has 
to take into account both the city and its surroundings and can usually done within an urban region that is also a planning unit. This is particularly adapted to medium-sized urban regions where usually both the city and its surroundings coexist in a planning unit. Secondly, a source of land-use information is also needed in order to map the different agri-urban patterns. Having a second landuse map can be useful to validate the agri-urban patterns identified, and further check the temporal dynamics of such land-use patterns. Thirdly, expert knowledge both on urban growth and planning and on farming in the area can also contribute to describe each pattern and the issues at stake and the proper tools to manage agriculture in each pattern.

\section{Conclusion}

The proposed case study can be considered as representative of a medium-sized urban region, affected by the contemporary dynamics of urbanization at the expense of agricultural areas and agricultural abandonment. The main findings of the study are related to the pattern dynamics of the agricultural lands within the urban region showing that urban regions can still preserve a productive function, althought it needs to be characterized and properly managed. Identifying agri-urban patterns is a preliminary step in the analysis of urban agricultural systems and the regulation and supply of ecosystem services. Our findings are important for urban planners and overcome the limits of using only land cover maps or agricultural census data as main supports for decision-making. Our work makes the spatial analysis readable and allow the application of regional objectives to local agri-urban patterns. Thus, it is possible to reason the importance of the spaces in relation to the urban densification, based on a balanced relationship between the urban and agricultural land.

\section{Disclosure statement}

No potential conflict of interest was reported by the authors.

\section{Funding}

This work was supported by the Scuola Sant'Anna of Pisa ["Studio del territorio rurale della pianura pisana"].

\section{ORCID}

Irune Ruiz-Martinez (iD http://orcid.org/0000-0002-7500-8408

Marta Debolini (iD http://orcid.org/0000-0002-9711-5482

Elisa Marraccini (iD http://orcid.org/0000-0002-2797-0758

\section{References}

Abrantes, P., Fontes, I., Gomes, E., \& Rocha, J. (2016). Compliance of land cover changes with municipal land use planning: Evidence from the Lisbon metropolitan region (1990-2007). Land Use Policy, 51(2), 120-134. https://doi. org/10.1016/j.landusepol.2015.10.023

Alberti, M. (2005). The effects of urban patterns on ecosystem function. International Regional Science Review, 28(2), 168-192. https://doi.org/10.1177/0160017605275160

Beckers, V., Poelmans, L., Rompaey, A. V., \& Dendoncker, N. (2020). The impact of urbanization on agricultural dynamics: a case study in Belgium. Journal of Land Use Science, O(0), 1-18. https://doi.org/10.1080/1747423X.2020.1769211

Beckie, M.A., Kennedy, E.H., \& Wittman, H. (2012). Scaling up alternative food networks: Farmers' markets and the role of clustering in western Canada. Agriculture and Human Values, 29(3), 333-345. https://doi.org/10.1007/s10460-0129359-9

Brabec, E., \& Smith, C. (2002). Agricultural land fragmentation: The spatial effects of three land protection strategies in the eastern United States. Landscape and Urban Planning, 58(2-4), 255-268. https://doi.org/10.1016/S0169-2046(01) 00225-0 
Çakir, G., Ün, C., Baskent, E.Z., Köse, S., Sivrikaya, F., \& Keleş, S. (2008). Evaluating urbanization, fragmentation and land use/land cover change pattern in Istanbul city, Turkey from 1971 TO 2002. Land Degradation \& Development, 19(6), 663-675. https://doi.org/10.1002/ldr.859

Carrasco, J.S., \& Puebla, J.M.A. (2014). Delimitation and characterization of new urban spaces in Valencia. Boletín De La Asociación De Geografos Españoles, 64. https://bage.age-geografia.es/ojs/index.php/bage/article/view/1709

Catalán, B., Saurí, D., \& Serra, P. (2008). Urban sprawl in the Mediterranean?: Patterns of growth and change in the Barcelona metropolitan region 1993-2000. Landscape and Urban Planning, 85(3-4), 174-184. https://doi.org/10. 1016/j.landurbplan.2007.11.004

Ceccarelli, T., Bajocco, S., Perini, L.L., \& Salvati, L.L. (2014). Urbanisation and land take of high quality agricultural soilsExploring long-term land use changes and land capability in Northern Italy. International Journal of Environmental Research, 8(1), 181-192. https://doi.org/10.22059/ijer.2014.707

Chorianopoulos, I., Pagonis, T., Koukoulas, S., \& Drymoniti, S. (2010). Planning, competitiveness and sprawl in the Mediterranean city: The case of Athens. Cities, 27(4), 249-259. https://doi.org/10.1016/j.cities.2009.12.011

Comune di Pisa. (2008). Deliberazione de Consiglio Comunale n. 8 del 13/02/2008. Retrieved February 5, 2020, from https://www.comune.pisa.it/uploads/2013_03_14_15_33_54.pdf

Comune di Pisa | DD 17-Piano Strutturale di Area e Pianificazione Sovracomunale. (2015). Accessed the 20th of September 2020 at https://www.comune.pisa.it/it/ufficio/7154/DD-17-Piano-Strutturale-di-Area-e-PianificazioneSovracomunale.html

Comune di Pisa | Piano Strutturale Pisa-Cascina. (2020). Accessed the 20th of September 2020 at https://www.comune. pisa.it/it/ufficio-scheda/26930/Piano-Strutturale-Intercomunale.html

CORINE Land Cover. (2012). https://www.eea.europa.eu/data-and-maps/data/clc-2012-vector

Cretella, A. (2019). Alternative food and the urban institutional agenda: Challenges and insights from Pisa. Journal of Rural Studies, 69(5), 117-129. https://doi.org/10.1016/j.jrurstud.2019.04.005

Darly, S., \& Torre, A. (2013). Conflicts over farmland uses and the dynamics of "agri-urban" localities in the Greater Paris region: An empirical analysis based on daily regional press and field interviews. Land Use Policy, 33(4), 90-99. https:// doi.org/10.1016/j.landusepol.2012.12.014

Debolini, M., Marraccini, E., Dubeuf, J.P., Geijzendorffer, I.R., Guerra, C., Simon, M., Targetti, S., \& Napoléone, C. (2018). Land and farming system dynamics and their drivers in the Mediterranean basin. Land Use Policy, 75(6), 702-710. https://doi.org/10.1016/j.landusepol.2017.07.010

Debolini, M., Valette, E., François, M., \& Chéry, J.-P. (2015). Mapping land use competition in the rural-urban fringe and future perspectives on land policies: A case study of Meknès (Morocco). Land Use Policy, 47(6), 373-381. https://doi. org/10.1016/j.landusepol.2015.01.035

Decoville, A., \& Schneider, M. (2015). Can the 2050 zero land take objective of the EU be reliably monitored? A comparative study. Journal of Land Use Science, 11, 1-19. https://doi.org/10.1080/1747423X.2014.994567

Dura-Guimera, A. (2003). Population deconcentration and social restructuring in Barcelona, a European Mediterranean city. Cities, 20(6), 387-394. https://doi.org/10.1016/j.cities.2003.08.004

Esri, I. (2008). ArcGIS 9.3. Environmental Systems Research Institute

European Environment Agency. (EEAb). (2018). Land take in Europe [Indicator Assessment]. https://www.eea.europa.eu/ data-and-maps/indicators/land-take-3/assessment

EEA 2019-Land and soil in Europe-European Environment Agency. (s. f.). [Publication]. Accessed the 19th of October 2020 at https://www.eea.europa.eu/publications/eea-signals-2019-land

Filippini, R., De Noni, I., Corsi, S., Spigarolo, R., \& Bocchi, S. (2018). Sustainable school food procurement: What factors do affect the introduction and the increase of organic food? Food Policy, 76(4), 109-119. https://doi.org/10.1016/j. foodpol.2018.03.011

Filippini, R., Lardon, S., Bonari, E., \& Marraccini, E. (2018). Unraveling the contribution of periurban farming systems to urban food security in developed countries. Agronomy for Sustainable Development, 38(2), 21. https://doi.org/10. 1007/s13593-018-0499-1

Filippini, R., Mazzocchi, C., \& Corsi, S. (2019). The contribution of urban food policies toward food security in developing and developed countries: A network analysis approach. Sustainable Cities and Society, 47(5), 101506. https://doi.org/ 10.1016/j.scs.2019.101506

Forman, R.T.T. (1995). Some general principles of landscape and regional ecology. Landscape Ecology, 10(3), $133-142$. https://doi.org/10.1007/BF00133027

Forman, R.T.T. (2008). Urban regions: Ecology and planning beyond the city. Cambridge University Press.

From Farm to Fork | European Commission. (s. f.). Accessed the 19th of October 2020 at https://ec.europa.eu/info/ strategy/priorities-2019-2024/european-green-deal/actions-being-taken-eu/farm-fork_en

Galli, M., Lardon, S., Marraccini, E., \& Bonari, E. (2010). Agricultural management in peri-urban areas. The experience of an international workshop. Felice Editore.

Geoscopio cartoteca-Regione Toscana. (2016). Sistema Informativo Territoriale ed Ambientale. GEOscopio WMS. http://www502.regione.toscana.it/-/geoscopio-wms

Giacchè, G., Torquati, B., Scazzosi, L., \& Branduini, P. (2012). Le pacte agriurbain de la vallée ombrienne et les districts agricoles et culturels de Milan. Projets de paysage, 1. 
Gonçalves, J., Gomes, M. C., Ezequiel, S., Moreira, F., \& Loupa-Ramos, I. (2017). Differentiating peri-urban areas: A transdisciplinary approach towards a typology. Land Use Policy, 63(4), 331-341. https://doi.org/10.1016/j.landuse pol.2017.01.041

Gounaridis, D., Chorianopoulos, I., \& Koukoulas, S. (2018). Exploring prospective urban growth trends under different economic outlooks and land-use planning scenarios: The case of Athens. Applied Geography, 90(1), 134-144. https:// doi.org/10.1016/j.apgeog.2017.12.001

GRASS Development Team. (2017). Geographic Resources Analysis Support System (GRASS GIS) Software, Version 7.2. Open Source Geospatial Foundation. http://grass.osgeo.org

Gren, Å., \& Andersson, E. (2018). Being efficient and green by rethinking the urban-rural divide-Combining urban expansion and food production by integrating an ecosystem service perspective into urban planning. Sustainable Cities and Society, 40(7), 75-82. https://doi.org/10.1016/j.scs.2018.02.031

Gunawardena, K.R., Wells, M.J., \& Kershaw, T. (2017). Utilising green and bluespace to mitigate urban heat island intensity. Science of the Total Environment, 584-585(4), 1040-1055. https://doi.org/10.1016/j.scitotenv.2017.01.158

Gurrutxaga San Vicente, M. (2003). Índices de fragmentación y conectividad para el indicador de biodiversidad y paisaje de la CAPV. http://www.proyectopandora.es/wp-content/uploads/Bibliografia/10161219_indices_fragmentacion.pdf

Jiang, Y., \& Swallow, S.K. (2015). Providing an ecologically sound community landscape at the urban-rural fringe: A conceptual, integrated model. Journal of Land Use Science, 10(3), 323-341. https://doi.org/10.1080/1747423X.2014. 898103

Kloosterman, R.C., \& Musterd, S. (2001). The polycentric urban region: Towards a research agenda. Urban Studies, 38(4), 623-633. https://doi.org/10.1080/00420980120035259

Kunzmann, K.R. (2010). Medium-sized towns, strategic planning and creative governance. In M. Cerreta, G. Concilio, \& V. Monno (Eds.), Making strategies in spatial planning (pp. 27-45). Springer. https://doi.org/10.1007/978-90-481-31068_2

La Rosa, D., \& Privitera, R. (2013). Characterization of non-urbanized areas for land-use planning of agricultural and green infrastructure in urban contexts. Landscape and Urban Planning, 109(1), 94-106. https://doi.org/10.1016/j.landurb plan.2012.05.012

Lardon, S., Houdart, M., Loudiyi, S., Filippini, R., \& Marraccini, E. (2017). Food, integrating urban and agricultural dynamics in Pisa, Italy. In C.-T. Soulard, C. Perrin, \& E. Valette (Eds.), Toward sustainable relations between agriculture and the city (pp. 15-31). Springer International Publishing. https://doi.org/10.1007/978-3-319-71037-2_2

Land recycling and densification-European Environment Agency. (s. f.). [Indicator Assessment]. Accessed the 19th of October 2020 at https://www.eea.europa.eu/data-and-maps/indicators/land-recycling-and-densification/assess ment-1

Land take-European Environment Agency. (s. f.). [Indicator Assessment]. Accessed the 19th of October 2020 at https:// www.eea.europa.eu/data-and-maps/indicators/land-take-2/assessment-1

Lovell, S.T. (2010). Multifunctional urban agriculture for sustainable land use planning in the United States. Sustainability, 2(8), 2499-2522. https://doi.org/10.3390/su2082499

Lovell, S.T., \& Taylor, J.R. (2013). Supplying urban ecosystem services through multifunctional green infrastructure in the United States. Landscape Ecology, 28(8), 1447-1463. https://doi.org/10.1007/s10980-013-9912-y

Marraccini, E., Debolini, M., Moulery, M., Abrantes, P., Bouchier, A., Chéry, J.-P., Sanz Sanz, E., Sabbatini, T., \& Napoleone, C. (2015). Common features and different trajectories of land cover changes in six Western Mediterranean urban regions. Applied Geography, 62(8), 347-356. https://doi.org/10.1016/j.apgeog.2015.05.004

Marraccini, E., Lardon, S., Loudiyi, S., Giacché, G., \& Bonari, E. (2013). Sustainability of agriculture in Mediterranean periurban areas: Issues and agriurban projects in the Pisan region (Tuscany, Italy). Cahiers Agricultures, 6, 517-525. https://doi.org/10.1684/agr.2013.0658

Marraccini, E., Lardon, S., \& Sabbatini, T. (2017). Les configurations spatiales agri-urbaines. Pour integrer l'agriculture dans I'amenagement des territories urbains. Spatial Analysis and GEOmatics, 2017(8). https://hal.archives-ouvertes.fr/ hal-01649748.

Mawois, M., Aubry, C., \& Le Bail, M. (2011). Can farmers extend their cultivation areas in urban agriculture? A contribution from agronomic analysis of market gardening systems around Mahajanga (Madagascar). Land Use Policy, 28(2), 434-445. https://doi.org/10.1016/j.landusepol.2010.09.004

McGarigal, K., \& Marks, B.J. (1995). Spatial pattern analysis program for quantifying landscape structure. Gen. Tech. Rep. PNW-GTR-351. US Department of Agriculture, Forest Service, Pacific Northwest Research Station.

Meraner, M., Pölling, B., \& Finger, R. (2018). Diversification in peri-urban agriculture: A case study in the Ruhr metropolitan region. Journal of Land Use Science, 13(3), 284-300. https://doi.org/10.1080/1747423X.2018.1529830

Mok, H.-F., Williamson, V.G., Grove, J.R., Burry, K., Barker, S.F., \& Hamilton, A.J. (2014). Strawberry fields forever? Urban agriculture in developed countries: A review. Agronomy for Sustainable Development, 34(1), 21-43. https://doi.org/10. 1007/s13593-013-0156-7

Moragues-Faus, A., \& Marceau, A. (2018). Measuring progress in sustainable food cities: An indicators toolbox for action. Sustainability, 11(1), 45. https://doi.org/10.3390/su11010045 
Moreira, F., Fontes, I., Dias, S., Silva, J.B.E., \& Loupa-Ramos, I. (2016). Contrasting static versus dynamic-based typologies of land cover patterns in the Lisbon metropolitan area: Towards a better understanding of peri-urban areas. Applied Geography, 75(10), 49-59. https://doi.org/10.1016/j.apgeog.2016.08.004

Morgan, K. (2015). Nourishing the city: The rise of the urban food question in the global north. Urban Studies, 52(8), 1379-1394. https://doi.org/10.1177/0042098014534902

Morote, Á.-F., \& Hernández, M. (2016). Urban sprawl and its effects on water demand: A case study of Alicante, Spain. Land Use Policy, 50(1), 352-362. https://doi.org/10.1016/j.landusepol.2015.06.032

OECD. 2020. Urban population by city size (indicator). Retrieved February 2, 2020, from https://doi.org/10.1787/b4332f92en

Opitz, I., Berges, R., Piorr, A., \& Krikser, T. (2016). Contributing to food security in urban areas: Differences between urban agriculture and peri-urban agriculture in the global north. Agriculture and Human Values, 33(2), 341-358. https://doi. org/10.1007/s10460-015-9610-2

Paül, V., \& McKenzie, F.H. (2013). Peri-urban farmland conservation and development of alternative food networks: Insights from a case-study area in metropolitan Barcelona (Catalonia, Spain). Land Use Policy, 30(1), 94-105. https:// doi.org/10.1016/j.landusepol.2012.02.009

Pileri, P., \& Maggi, M. (2010). Sustainable planning? First results in land uptakes in rural, natural and protected areas: The Lombardia case study (Italy). Journal of Land Use Science, 5(2), 105-122. https://doi.org/10.1080/1747423X.2010. 481078

Prytherch, D.L., \& Boira Maiques, J.V. (2009). City profile: Valencia. Cities, 26(2), 103-115. https://doi.org/10.1016/j.cities. 2008.11.004

QGIS Development Team. (2020). QGIS Geographic Information System. Open Source Geospatial Foundation Project. http://qgis.osgeo.org

Regione Toscana. Piano di indirizzo territoriale con valenza di piano paesaggistico. (s. f.). Accessed the 19th of October 2020 at https://www.regione.toscana.it/-/piano-di-indirizzo-territoriale-con-valenza-di-piano-paesaggistico

Regione Toscana. 2016. Sistema Informativo Territoriale ed Ambientale. GEOscopio WMS. http://www502.regione.tos cana.it/-/geoscopio-wms

Renting, H., Marsden, T.K., \& Banks, J. (2003). Understanding alternative food networks: Exploring the role of short food supply chains in rural development. Environment and Planning A: Economy and Space, 35(3), 393-411. https://doi.org/ 10.1068/a3510

Rizzo, D., Marraccini, E., Lardon, S., Rapey, H., Debolini, M., Benoît, M., \& Thenail, C. (2013). Farming systems designing landscapes: Land management units at the interface between agronomy and geography. Geografisk Tidsskrift-Danish Journal of Geography, 113(2), 71-86. https://doi.org/10.1080/00167223.2013.849391

Romano, B., \& Zullo, F. (2014). Land urbanization in Central Italy: 50 years of evolution. Journal of Land Use Science, 9(2), 143-164. https://doi.org/10.1080/1747423X.2012.754963

Romero-Calcerrada, R., \& Perry, G.L.W. (2004). The role of land abandonment in landscape dynamics in the SPA 'Encinares del río Alberche y Cofio, Central Spain, 1984-1999. Landscape and Urban Planning, 66(4), $217-232$. https://doi.org/10.1016/S0169-2046(03)00112-9

Ruiz-Martinez, I., Marraccini, E., Debolini, M., \& Bonari, E. (2015). Indicators of agricultural intensity and intensification: A review of the literature. Italian Journal of Agronomy, 10(2), 74. https://doi.org/10.4081/ija.2015.656

Salvati, L. (2013). Monitoring high-quality soil consumption driven by urban pressure in a growing city (Rome, Italy). Cities, 31(4), 349-356. https://doi.org/10.1016/j.cities.2012.11.001

Salvati, L. (2015). Lost in complexity, found in dispersion: 'Peripheral' development and deregulated urban growth in Rome. Cities, 47(9), 73-80. https://doi.org/10.1016/j.cities.2015.04.001

Salvati, L., Gemmiti, R., \& Perini, L. (2012). Land degradation in Mediterranean urban areas: An unexplored link with planning?: Land degradation in Mediterranean urban areas. Area, 44(3), 317-325. https://doi.org/10.1111/j.14754762.2012.01083.x

Salvati, L., Munafo, M., Morelli, V.G., \& Sabbi, A. (2012). Low-density settlements and land use changes in a Mediterranean urban region. Landscape and Urban Planning, 105(1-2), 43-52. https://doi.org/10.1016/j.landurbplan.2011.11.020

Salvati, L., Sateriano, A., \& Bajocco, S. (2013). To grow or to sprawl? Land cover relationships in a Mediterranean city region and implications for land use management. Cities, 30(2), 113-121. https://doi.org/10.1016/j.cities.2012.01.007

Sanz Sanz, E., Martinetti, D., \& Napoléone, C. (2018). Operational modelling of peri-urban farmland for public action in Mediterranean context. Land Use Policy, 75(6), 757-771. https://doi.org/10.1016/j.landusepol.2018.04.003

Sanz Sanz, E., Napoléone, C., Hubert, B., Mata, R., \& Giorgis, S. (2017). Repenser la planification urbaine à partir des espaces agricoles: Une méthodologie opérationnelle à l'échelle intercommunale. Revue d'Économie Régionale \& Urbaine, Juin(3), 511. https://doi.org/10.3917/reru.173.0511

Scheromm, P., \& Soulard, C. (2018). The landscapes of professional farms in mid-sized cities, France: Professionnal farming in mid-sized cities. Geographical Research, 56(2), 154-166. https://doi.org/10.1111/1745-5871.12272

Semple, E.C. (1929). Irrigation and reclamation in the ancient Mediterranean region. Annals of the Association of American Geographers, 19(3), 111-148. https://doi.org/10.1080/00045602909357085

Serra, P., Saurí, D., \& Salvati, L. (2017). Peri-urban agriculture in Barcelona: Outlining landscape dynamics vis à vis socioenvironmental functions. Landscape Research, 43(5),1-19. https://doi.org/10.1080/01426397.2017.1336758 
Soulard, C.-T., Valette, E., Perrin, C., Abrantes, P.C., Anthopoulou, T., Benjaballah, O., Bouchemal, S., Dugué, P., Amrani, M. E., Lardon, S., Marraccini, E., Mousselin, G., Napoleone, C., \& Paoli, J.-C. (2017). Peri-urban agro-ecosystems in the Mediterranean: Diversity, dynamics, and drivers. Regional Environmental Change , 18(3), 651-662. https://doi.org/10. 1007/s10113-017-1102-z

Taubenböck, H., Wiesner, M., Felbier, A., Marconcini, M., Esch, T., \& Dech, S. (2014). New dimensions of urban landscapes: The spatio-temporal evolution from a polynuclei area to a mega-region based on remote sensing data. Applied Geography, 47(2), 137-153. https://doi.org/10.1016/j.apgeog.2013.12.002

Tavares, A.O., Pato, R.L., \& Magalhães, M.C. (2012). Spatial and temporal land use change and occupation over the last half century in a peri-urban area. Applied Geography, 34(5), 432-444. https://doi.org/10.1016/j.apgeog.2012.01.009

Tedesco, C., Petit, C., Billen, G., Garnier, J., \& Personne, E. (2017). Potential for recoupling production and consumption in peri-urban territories: The case-study of the Saclay plateau near Paris, France. Food Policy, 69(5), 35-45. https://doi. org/10.1016/j.foodpol.2017.03.006

Wadduwage, S. (2018). Peri-urban agricultural land vulnerability due to urban sprawl - a multi-criteria spatially-explicit scenario analysis. Journal of Land Use Science, 13(3), 358-374. https://doi.org/10.1080/1747423X.2018.1530312

Zasada, I. (2011). Multifunctional peri-urban agriculture-A review of societal demands and the provision of goods and services by farming. Land Use Policy, 28(4), 639-648. https://doi.org/10.1016/j.landusepol.2011.01.008

Zasada, I., Berges, R., Hilgendorf, J., \& Piorr, A. (2013). Horsekeeping and the peri-urban development in the Berlin metropolitan region. Journal of Land Use Science, 8(2), 199-214. https://doi.org/10.1080/1747423X.2011.628706

Zdruli, P. (2014). Land resources of the mediterranean: Status, pressures, trends and impacts on future regional development: Land resources, population growth and mediterranean region development. Land Degradation \& Development, 25(4), 373-384. https://doi.org/10.1002/ldr.2150 